\title{
Experimental Study on the Anisotropic Cracking Behavior of Shale under Compression and Tension
}

\author{
Lei Yang ${ }^{1}$, Xiangchao Sheng ${ }^{1}$, Ningbo $\mathrm{Li}^{1}$, Xujin $\mathrm{Ma}^{1}$, Xiaolong Wang ${ }^{1}$, and Pai Wang ${ }^{1}$ \\ ${ }^{1}$ Shandong University - Qianfoshan Campus
}

February 26, 2022

\begin{abstract}
To gain insight into the anisotropic mechanical properties and failure behavior of shale, the cracking behavior of shale under compression and tension was investigated experimentally from the macroscopic and microscopic perspectives. The uniaxial compression tests were first carried out, and the effects of bedding plane on the generation of microcracks were analyzed through the technology of nuclear magnetic resonance. Then, the Brazilian splitting and confocal laser scanning microscopy tests were performed, and the corresponding relation between the failure mode and the fracture surface morphology was discussed. The results reveal that the mechanical properties and failure modes of shale are affected significantly by the existence of bedding planes. The distribution characteristics of microflaw radius and porosity change significantly due to the action of uniaxial compression, and the highest porosity of newly-generated microcracks is that of the $0^{\circ}$ specimen. The newly-generated microflaws in $0^{\circ}, 30^{\circ}$ and $90^{\circ}$ specimens are mainly contributed by seepage microflaws, while those in $60^{\circ}$ specimen are mainly contributed by capillary microflaws. In the Brazilian splitting test, the fracture surface morphology of the specimen is significantly affected by the bedding angle, and the fracture surface morphology of the specimen is closely related to the failure mode and mechanism.
\end{abstract}

\section{Hosted file}

Manuscript .docx available at https://authorea.com/users/462441/articles/557866-experimentalstudy-on-the-anisotropic-cracking-behavior-of-shale-under-compression-and-tension 